\section{ELDER ABUSE DECISION SUPPORT SYSTEM}

K.J. Conrad ${ }^{2}$, M. Iris ${ }^{3}$, P. Liu'1 1 1. UCSF, Walnut Creek, California, 2. University of Illinois at Chicago, Chicago, Illinois, 3. Leonard Schanfield Research Institute, Chicago, Illinois

Objectives. The Elder Abuse Decision Support System (EADSS) was designed to meet the critical need for improved methods for assessment and substantiation of elder mistreatment, using a web-based system with standardized assessment measures. Methods. Six Illinois agencies participated in the field test. One-year pre/post analyses assessed substantiation results, using Illinois' standard investigation procedure as a comparison. Pre/post acceptability was assessed with caseworkers. Focus groups with APS staff examined users' experiences. Validity of measures was assessed using Cronbach's alpha and receiver operator characteristic curve analyses with final substantiation decision as criterion. Results. Increased substantiation of abuse was found. Regarding acceptability, the two systems were found to have differing strengths and weaknesses. Outcome measures had high validity estimates while focus groups indicated directions for improvement. Significance. This study was a successful proof of concept that data collected in the field would be useful for clinical purposes as well as for research.

\section{EVALUATING CALIFORNIA'S READINESS TO PARTICIPATE IN THE NATIONAL ADULT MALTREATMENT REPORTING SYSTEM}

P. Liu ${ }^{1}$, T. Hedani ${ }^{8}$, L. Delagrammatikas ${ }^{2}$, J. Nielsen ${ }^{3}$, S. Lindberg ${ }^{4}$, C. Alire ${ }^{5}$ S. Skezas ${ }^{6}$, R. MacKenzie ${ }^{7}$, 1. UCSF, Walnut Creek, California, 2. California Department of Social Services, Sacramento, California, 3. City/County of San Francisco, San Francisco, California, 4. Orange County, Orange, California, 5. San Diego County, San Diego, California, 6. Santa Cruz County, Santa Cruz, California, 7. Sacramento County, Sacramento, California, 8. Institute on Aging, San Francisco, California

California's Adult Protective Services (APS) program investigates approximately $15 \%$ of all elder abuse, neglect, and exploitation reports in the country. However, as a countybased system, each of the 58 counties operates independently. Collecting and submitting state level data to the National Adult Maltreatment Reporting System (NAMRS) will be a challenge for the state. Two surveys were launched to investigate data systems used and data elements collected in each county. Moreover, in-depth interviews were conducted with 14 counties' 24 APS supervisor, manager, or/and director. Six more interviews are scheduled for the remainder of July. Preliminary findings revealed that one third of the counties track data without any technological support, and expressed the desire to acquire help. Other counties using a case management system vary in the system used and often differ on data elements collected. Challenges including administrative, budgetary, and political issues will be summarized, and a blueprint for next steps in California will be outlined.

\section{GOAL ATTAINMENT SCALING: MEASURING CHANGE IN APS ELDER ABUSE INTERVENTION}

D. Burnes ${ }^{1}$, M.S. Lachs ${ }^{2}$, 1. University of Toronto, Toronto, Ontario, Canada, 2. Weill Cornell Medical College, New York City, New York
Adult protective services (APS) involvement with elder abuse cases carries the primary objective to reduce risk of re-victimization. Knowledge of effective APS intervention in elder abuse cases is scant. Intervention research is constrained by an absence of outcome measures that can assess change on re-victimization risk status over the course of intervention. Re-victimization risk is difficult to measure due to its multifarious/heterogeneous nature across cases. This presentation will present findings from a prospective study with the State of Maine APS to examine the feasibility of goal attainment scaling (GAS). GAS is a client-centered measure of client change that accommodates case heterogeneity. Based on qualitative interviews with APS caseworkers/ management, we will present themes of GAS implementation challenges, feasibility, and best practices. We will also present caseworker focus group findings on constructing a menu of pre-worded GAS scales, which span several areas of risk including living arrangement, safety planning, and social support/engagement.

\section{DEVELOPING AN UNDUE INFLUENCE SCREENING TOOL FOR ADULT PROTECTIVE SERVICES}

A.E. Navarro ${ }^{1}$, M. Joy ${ }^{2}$, L. Nerenberg ${ }^{3}$, 1. University of Southern California, Los Angeles, California, 2. Superior Court (ret.), San Francisco, California, 3. California Elder Justice Coalition, San Francisco, California

In 2020, California baby boomers start turning 85, increasing by $143 \%$ (CDA, 2012). Given the added risk of experiencing cognitive decline and physical fragility, the need for Adult Protective Services (APS) efficiencies will be critical. Training and screening tools that recognize financial abuse have also been recommended within the APS field. In a report-Recommended Minimal Program Standards-published by the National Adult Protective Services Association (2013), the importance of APS training in evaluating clients' capacity to manage, use, and preserve assets is highlighted.

This qualitative project examined the diffusion of knowledge about undue influence among 33 APS personnel in two California county-based service organizations to determine the need for a screening tool. Among diverse personnel, $6 \%$ had knowledge of the state definition (effective1/1/2014), while $94 \%$ had previous training. Participant feedback of a drafted screening tool designed to screen undue influence risk among vulnerable adults was positively received.

\section{SESSION 4725 (SYMPOSIUM)}

\section{LONG-TERM CARE IN ASIA, THE U.S., AND EUROPE}

Chair: L. Polivka, Claude Pepper Center, Tallahassee,

Florida

Co-Chair: B. Luo, Western Washington University,

Bellingham, Washington

Long-term care (LTC) is rapidly emerging as a major public policy issue in countries across the developed and developing worlds as their older populations grow at unprecedented rates. Nations vary widely in the kinds of LTC services they provide, how they pay for them and in how they are administered. The presenters in this symposium will demonstrate this variance in their analyses of LTC policies and administrative structures in several countries from Asia to Europe and 